Rehabilitation Research and Training Center for Economic Research on Employment Policy for Persons with Disabilities

Report:

\title{
Health Insurance Coverage Among Youth and Young Adults with Work Limitations
}

Bonnie O’Day

David C. Stapleton

Ann E. Horvath-Rose

Cornell University Institute for Policy Research 
For further information about this paper contact:

Bonnie O'Day

Cornell University Institute for Policy Research

1341 22nd Street, NW

Washington, DC 20037-3010

tel (202) 223-7670

emailbo29@cornell.edu

web www.cuipr.cornell.edu

This report is being distributed by the Rehabilitation Research and Training Center for Economic Research on Employment Policy for Persons with Disabilities at Cornell University.

This center is funded to Cornell University, in collaboration with The Urban Institute (Washington, DC), by the U.S. Department of Education, National Institute on Disability and Rehabilitation Research (No. H133B980038). The contents of this paper do not necessarily represent the policy of the Department of Education, and you should not assume endorsement by the Federal Government (Edgar, 75.620 (b)). The views in this policy brief are not necessarily endorsed by Cornell University or the American Association of People with Disabilities.

The Co-Principal Investigators are:

Susanne M. Bruyère—Director, Employment and Disability Institute, School of Industrial and Labor Relations, Extension Division, Cornell University

Richard V. Burkhauser-Sarah Gibson Blanding Professor and Chair, Department of Policy Analysis and Management, College of Human Ecology, Cornell University

David C. Stapleton—Director, Cornell University Institute for Policy Research 


\title{
Health Insurance Coverage among Youth and Young Adults with Work Limitations
}

\author{
Bonnie O’Day, Ph.D.*** \\ David C. Stapleton, Ph.D.** \\ Ann E. Horvath-Rose, Ph.D**. \\ Cornell Institute for Policy Research \\ $134122^{\text {nd }}$ Street NW \\ Washington, DC 20037
}

*Corresponding author.

2455 North Stevens Street, Alexandria VA 22311

Phone (703)845-3436;

Fax (866) 371-1633;

email bo29@cornell.edu

Acknowledgement: This paper has benefited substantially from the comments of Gina Livermore and several reviewers, as well as the research assistance of Jennifer Chunn and Torrey Androski. We are grateful for the financial support provided by the U.S. Department of Education, National Institute on Disability and Rehabilitation Research (Cooperative Agreement No. H133B980038). The contents of this paper do not necessarily represent the policy of the Department of Education, and you should not assume endorsement by the Federal Government (Edgar, 75.620 (b)).

January, 2007 


\title{
Health Insurance Coverage among Youth and Young Adults with Work Limitations
}

\author{
Abstract \\ This paper explores health insurance coverage trends for youth (age 15-18) and young \\ adults (age 19-29) with work limitations using data from the Current Population Survey. In 2000 \\ those in the young work-limited population were substantially more likely to have insurance \\ coverage than their counterparts in the not work-limited population. They were much more \\ likely to have public coverage and much less likely to have only private coverage. Insurance \\ coverage for this population increased substantially between 1989 and 2000, in contrast to a \\ decline for the not work-limited population. We discuss the probable contributions of policy \\ reforms and the decline in employment of people with work limitations to these trends.
}


Evidence suggests that despite recent efforts to provide health insurance for people with disabilities and low-income working mothers, health insurance coverage rates for working-age individuals with disabilities have declined. Data from the National Medical Expenditure Survey (NMES) and the Medical Expenditure Panel Survey (MEPS) show that, between 1987 and 1996/97, the number of people with disabilities ages 25-61 who lack any public or private health insurance coverage increased. Although reliance on the public benefit system increased over this period, private coverage fell enough to result in a net loss of coverage for this age group (Hill, Livermore and Houtenville, 2003). This paper addresses a current knowledge gap--public and private health care coverage among youth (age 15-18) and young adults (age 19-29) with work limitations.

Health insurance coverage among youth and young adults with work limitations is an important issue for several reasons. First, the Current Population Survey (CPS) shows that there were 4.4 million persons ages 15 to 29 with work limitations in the non-institutionalized population in 2000, representing 2.6 percent of all persons in this age group. Second, the availability of adequate health insurance can have a significant impact upon the ability of youth and young adults with disabilities to successfully make the transition to adulthood. Loss of Medicare or Medicaid has often been cited as the most significant reason that Supplemental Security Income (SSI) and Social Security Disability Insurance (SSDI) beneficiaries do not leave the rolls for employment (Stapleton et al., 1998; Hill et al., 2003). Health insurance also provides access to medical equipment and technology, in-home assistance, and community support that enables people with disabilities to live independently.

Third, employer coverage for workers and their dependents has declined markedly over the last several decades, primarily because fewer employees purchased the health insurance they 
were offered due to increased employee costs (Cutler, 2002). Employees are even less likely to purchase coverage for dependents due to increased costs. We would like to know how much this decline in coverage has affected youth and young adults with disabilities.

Fourth, significant policy reforms have aimed to increase the health care coverage of working mothers, children, and people with disabilities. A few of these reforms were primarily designed to increase coverage, but others were designed to increase employment of welfare recipients or provide SSI to low-income families with a disabled child.

Welfare reform is the most well known of the policy changes that took place in the 1990s. In 1993, Congress greatly increased the Earned Income Tax Credit (EITC) for lowincome parents, thereby increasing the incentive of welfare parents to work. In the following years, several states experimented with ways to increase the earnings and tax credit income of welfare parents and reduce their reliance on benefits. In 1996, Congress passed the Personal Responsibility and Work Opportunity Reform Act (PRWORA), endorsing for the first time the expectation that parents of both genders will work to support their families when necessary, and will rely on welfare only as a temporary last resort. PRWORA replaced the Aid to Families with Dependent Children (AFDC) program with the Temporary Assistance for Needy Families (TANF) block grants to states. This new law (as well as some earlier reforms in individual states) places time limits on receipt of welfare benefits, imposes strict work requirements on recipients, and makes welfare benefits conditional on cooperation with paternity establishment.

PRWORA also gave states block grants to reduce their welfare rolls by providing job placement support, child care, transportation assistance, one-time emergency assistance payments, assistance in obtaining the EITC, and assistance in maintaining Medicaid eligibility. Special provisions were intended to preserve Medicaid eligibility for children, and, to a lesser 
extent, their parents. Despite Congressional intent, however, many recipients lost their Medicaid coverage when they lost their welfare benefits (Garret and Holahan, 2000). One reason is that some obtained coverage through an employer, but this accounts for a relatively small share of welfare recipients who lost coverage. Another reason is that administrative changes made enrollment in Medicaid more difficult (Ellwood and Ku, 1998). Eligibility rules to include those who would have been categorically eligible before welfare reform added complexity; administrative links between Medicaid coverage and welfare receipt that had been relied on to ensure that welfare recipients were enrolled in Medicaid no longer applied for many. Some achieved income levels that made them ineligible after an initial grace period expired. Some may have been deterred from enrollment by the burden of the enrollment process or the stigma attached to enrollment, especially if they believed that they could enroll later, in the event of a substantial need for medical services

The 1990 Zebley $v$ Sullivan (493 US 521) court decision dramatically expanded eligibility for children under the SSI program, thereby greatly increasing the number of children with disabilities eligible for cash benefits and Medicaid (Garrett \& Glied, 1997). Although some of these children had Medicaid coverage as members of AFDC households, others were from relatively low income households that did not qualify for AFDC or Medicaid.

Concerns about the size of the expansion of SSI following Zebley led to limitations in child eligibility for SSI as part of PRWORA (Stapleton, et al., 2001/2002). In the next few years, some child SSI recipients lost eligibility, primarily because of the elimination of Individualized Functional Assessments for children. Those under 18 were allowed to keep their Medicaid if they would have qualified under pre-PRWORA criteria, so the effect of this tightening on Medicaid enrollment may have been delayed. In addition, SSI child beneficiaries must now be 
re-determined eligible for SSI benefits at age 18, under adult criteria; those found ineligible lose their Medicaid benefits unless they qualify under some other Medicaid category.

Social Security Administration (SSA) estimates of SSI participation from 1991 to 2004 for those in three age groups: $13-17,18-21$, and 22 to 29 show the large effect of the postZebley expansion on participation by those age 13 to 17 (Figure 1). ${ }^{1}$ From 1991 to 1996, participation in this age group increased from 8.2 percent to 16.8 percent. The effect of the tightening of standards for this age group after PRWORA is also apparent in the late 1990s, with the participation rate dropping to 14.4 percent in 2000, but by 2004 the participation rate had reached a new high, 17.2 percent. Also apparent is the delayed, indirect effect of the post-Zebley expansion on participation for those age 18 to 21, rising from 8.0 percent in 1991 to a peak of 16.3 percent in 1996, and continuing to follow the pattern for those age 13 to 17, but with a lag, through 2004. Comparison of the statistics for those 18 to 21 to the statistics for those age 13 to 17 suggests that the age 18 redeterminations do not lead to substantial reductions in the number continuing on SSI after age 18. The statistics are also consistent with smaller delayed effects of child SSI expansions on SSI participation by those aged 22 to 29 .

The State Children’s Health Insurance Program (SCHIP) was, in part, a reaction to declines in Medicaid coverage after passage of PRWORA. SCHIP provided medical assistance for children in low-income families. Included as Title XXI of the Social Security Act in the Balanced Budget Act of 1997, SCHIP provides public insurance, generally Medicaid, coverage for low-income children under age 19 whose families earn too much to be eligible for Medicaid, but who cannot afford any private health insurance.

\footnotetext{
${ }^{1}$ We rely on administrative data rather than the CPS for these statistics because self-reports of SSI receipt from the CPS are not reliable, in part because of under-reporting, in part because of inadequate information on which individual(s) in a household receive benefits, and in part because of confusion with the SSDI program.
} 
In summary, the large number of youth and young adults with work limitations, and the importance of health care coverage to these individuals make this an important topic for consideration. Social forces, such as the decline in employer coverage, along with the policy reforms mentioned above, have likely had an impact on coverage. We propose study questions below and discuss potential impacts of policy reform in our concluding section.

We address the following questions:

1. To what extent are youth and young adults (15-29 year olds) with work limitations covered by health insurance, what type of coverage do they have (i.e., private versus public), how does their coverage vary by age, gender, and employment status, and how does it compare to coverage for those in this age group without work limitations?

2. Did the overall health insurance coverage for youth and young adults with work limitations increase, decrease, or remain the same?

3. To what extent, if any, did public coverage replace private coverage?

4. To what extent do coverage changes vary across groups defined by gender, age and employment status, and to what extent do they reflect changes in the gender/age/employment status composition of the population? (e.g., to what extent is any change in coverage related to changes in employment status versus changes in private coverage for those who are employed?) 5. To what extent is variation in coverage changes across groups consistent with expectations, given the labor market and policy changes described above? We expect the following relationships:

- Declines in private coverage are more likely for young adults than for youth, because they are more likely than youth to be employed. They may also be observed for youth, however, because of declines in private employer coverage for their parents 
- The implementation of SCHIP and the SSI expansion under Zebley has direct effects for youth and young adults. Effects are likely larger for males because almost twothirds of SSI children are males. The 1996 SSI changes to child eligibility may have countered this effect on those under 18, but for many the effect may have been delayed because those losing SSI eligibility under these reforms remained eligible for Medicaid. New requirements for SSI redetermination at age 18, under adult rules, may have had a more immediate counterbalancing effect on Medicaid coverage for those 18 or over.

- PRWORA changes in family policy most likely affect public coverage for females with work limitations.

\section{Methods}

We use data from the Annual Demographic Survey (March supplement) of the Current Population Survey (CPS), an annual nationally representative cross-sectional survey of approximately 150,000 non-institutionalized civilians in 50,000 households, conducted by the Bureau of the Census for the Bureau of Labor Statistics. As the primary source of information on the labor force characteristics of the U.S. population, the CPS is rich in information about employment, unemployment, income, earnings, hours of work, program participation, health insurance, and educational attainment, as well as demographic characteristics including age, gender, race, marital status, and living arrangements.

Due to the relatively small number of youth and young adults with work limitations captured in each years sample, all statistics reported are based on data pooled over a three-year period centered on the year indicated. Thus, for instance, statistics for 2000 are based on the surveys for 1999 through 2001, conducted in March 2000, 2001 and 2002. 
Since 1981, the CPS has included the following question about work limitations, asked of the reference person in the household:

Does anyone in this household have a health limitation or disability which prevents them from working or which limits the kind or amount of work they can do? [If so,] who is that? (Anyone else?)

The CPS definition of work limitations can also include individuals with self-limiting conditions who do not have long-term limitations or disabilities.

The use of work limitation as a measure of disability is controversial (Hale, 2001; Hardy and Pavalko, 1986; Kaye, 2002; Kirchner, 1996; Kruse and Schur, 2000; McNeil 2000; Silverstein, 2005). There is little doubt that this method of identifying people with disabilities misses many individuals who might reasonably be considered to have a disability. This makes it problematic to draw conclusions about the characteristics of "people with disabilities" in a specific year based on the CPS. Research has shown however, that CPS-based trends in prevalence of work limitations and employment rates for people with work limitations are similar to those found in other surveys using alternative measures of disability, such as the National Health Interview Survey and the Survey of Income and Program Participation (Burkhauser et al., 2002; Burkhauser, Houtenville and Wittenburg, 2003; Kaye, 2003).

Nonetheless, changes in the environment, the labor market, public policy and selfdefinition may influence a person's answer to the work-limitation question, and such factors might themselves be changing. This is evident from the long-term trends in the prevalence of work limitations among youth and young adults (ages 15 to 29) (Figure 2). Prevalence increases during economic downturns and declines during expansions. Changes in self-reporting can also affect changes in the average characteristics of those who self-report (compositional changes); most obviously, people induced to report work limitations by a recession are very unlikely to be 
employed, so their addition to the population of those with work limitations decreases the number of individuals that are employed within that group.

Because most private insurance is obtained through employer groups, an increase in prevalence induced by a recession is likely to reduce the percentage of the work-limited population with any private health insurance. The same induced change in prevalence might either increase or reduce the percentage with public health insurance, depending on the extent to which those induced to report work limitations because of job loss obtain public coverage. To minimize the effects of changes in prevalence induced by the business cycle on the statistics, we focus on comparing statistics from two business cycle peaks, years preceding large declines in growth of real gross domestic product following long growth period, in 1989 and 2000.2

Another characteristic of the trends in Figure 2 is that there is a convergence between the prevalence of work limitations for young males and females over this two-decade period. As we have shown elsewhere, it appears that this convergence is due to both the family policy reforms of the 1990s and long-term trends in the labor force participation of women (Horvath-Rose, Stapleton, and O’Day, forthcoming). Hence, particularly for young women, it is important to consider the extent to which changes in health insurance coverage might reflect induced changes in the reporting of work limitations even when comparing the two business-cycle peak years.

The analysis is necessarily limited by the nature of the disability, health insurance and other questions asked in the CPS, but we consider the CPS to be the best starting point for such an analysis because: it is large enough to obtain reasonably precise estimates for many interesting population characteristics; it has been fielded annually in a very consistent fashion

\footnotetext{
${ }^{2}$ The growth rate of real GDP fell from 3.5 percent in 1989 to 1.9 percent in 1990 after 7 years of growth above three percent per year, and from 3.7 percent in 2000 to 0.8 percent in 2001, following 9 years of growth above 2.5 percent per year (President’s Council of Economic Advisors, 2005, Table B-4).
} 
over the last two decades; and it is the official federal source of population statistics for many of the outcomes of interest. Because the definition of disability used in this paper is based on work limitations, we refer to the population we study as persons with work limitations.

There are known limitations to the insurance information collected in the CPS. Respondents underreport enrollment in the two major public health insurance programs, Medicare and Medicaid (Mills, 2001). We also suspect that many confuse the two programs. For the age range we consider, however, Medicaid is the dominant program. Only the relatively small number in this age range who have been SSDI beneficiaries for at least 24 months (they must have completed sufficient quarters of work to be eligible for SSDI), who have End Stage Renal Disease, or who are disabled children of recipients of Social Security retirement or disability benefits would be eligible for Medicare. Hence, the changes in public health insurance reported here are dominated by changes in Medicaid coverage. Based on Mills (2001), we also suspect that the levels of public health insurance coverage we report are low, on the order of one or two percentage points. ${ }^{3}$

We included as covered by private health insurance all persons with health insurance coverage through their own employer, their spouse if living in the same household, and their parents or step-parents if they are children under the age of 25 and living in the same household. We did not use the answers to additional health insurance questions related to the coverage of these individuals themselves, and if we had some of those counted as having private coverage would have been counted as not having private coverage. Trends in this measure of private

3 Starting in 1999, the CPS added supplementary insurance questions to probe further for coverage when respondents reported no coverage in response to the CPS questions used in previous years. Mills (2001) found that these questions add one or two percentage points to public coverage, depending on the population group considered. As a result of these findings, the CPS continues to use the supplementary questions. We did not use them in our analysis, however, to ensure comparability of estimates for earlier years. 
coverage should be quite similar to those in a more accurate measure unless there are systematic changes in the extent of dependent coverage. Any trend toward employer tightening of eligibility for dependents, premium increases that discouraged employees from electing dependent coverage, or expanded opportunities to enroll dependents in public programs (e.g., SCHIP) would not show up in our estimates as a decline in private coverage for dependents as long as the employee remains covered. ${ }^{4}$

Insurance status is related to key demographic and economic factors as well as work limitation status: age, sex, and employment. Some changes in coverage may be due to changes in the composition of the population with respect to these characteristics. We use four age categories for the analysis (15-18, $19-21,22-25$ and $26-29)$, along with two sex and two employment status categories to define 16 groups.

We performed a "shift-share" analysis to separate the effects of "compositional changes" - changes in the distribution of youth and young adults with work limitations across these 16 groups -- on insurance status from the effects of changes in coverage within groups. ${ }^{5}$ The objective of this analysis is to aid in the interpretation of observed changes. Compositional changes reflect changes that would have occurred if all changes were due to changes in the distribution of the population across the 16 groups, with no change in coverage within each group. Using this methodology, we can determine, in a unified manner, the contribution of changes in each of the following to changes in overall coverage for youth and young adults with

\footnotetext{
${ }^{4}$ Although it is technically possible to revise the estimates of private coverage, we do not have the resources to do so.

${ }^{5}$ Shift-share analysis is most commonly used to better understand the contributions of industry-level growth to overall growth in a national or regional economy (see, for example, Hoover and Giarratani, 1985). Houtenville and Daly (2003) apply the technique to analysis of the role played by age, education, and health in trends in the employment rate of people with disabilities.
} 
work limitations: age composition; sex composition; employment status; coverage for males; coverage for females; coverage for those who are employed; and coverage for those who are not employed.

More specifically, the shift-share analysis separates the percentage point change in the percentage insured into two components: 1) the change in the composition of the youth/young adult population, and 2) the change in the percentage insured in each group. The overall percentage insured in any given year $\left(\mathrm{P}^{t}\right)$ is the sum of group percentages $\left(\mathrm{P}_{\mathrm{g}}^{\mathrm{t}}\right)$ weighted by group population shares $\left(\mathrm{S}_{\mathrm{g}}^{\mathrm{t}}\right)$ over all groups $(\mathrm{g}=1,2, \ldots, 16)$. The change in overall percentage insured from one year ( $\mathrm{t}$ ) to another year $\left(\mathrm{t}^{\prime}\right)$ is

$$
\mathrm{P}^{\mathrm{t}^{\prime}}-\mathrm{P}^{\mathrm{t}}=\sum_{\mathrm{g}=1}^{16}\left(\mathrm{P}_{\mathrm{g}}^{\mathrm{t}^{\prime}} \mathrm{S}_{\mathrm{g}}^{\mathrm{t}^{\prime}}\right)-\sum_{\mathrm{g}=1}^{16}\left(\mathrm{P}_{\mathrm{g}}^{\mathrm{t}} \mathrm{S}_{\mathrm{g}}^{\mathrm{t}}\right)
$$

This change can be rewritten as:

$$
\begin{aligned}
\mathrm{P}^{\mathrm{t}^{\prime}}-\mathrm{P}^{\mathrm{t}} & =\sum_{\mathrm{g}=1}^{16}\left(\left(\mathrm{~S}_{\mathrm{g}}^{\mathrm{t}^{\prime}}-\mathrm{S}_{\mathrm{g}}^{\mathrm{t}}\right)\left(\mathrm{P}_{\mathrm{g}}^{\mathrm{t}}-\mathrm{P}^{\mathrm{t}}\right)\right)+\sum_{\mathrm{g}=1}^{16}\left(\left(\mathrm{P}_{\mathrm{g}}^{\mathrm{t}^{\prime}}-\mathrm{P}_{\mathrm{g}}^{\mathrm{t}}\right) \mathrm{S}_{\mathrm{g}}^{\mathrm{t}^{\prime}}\right) \\
& =\sum_{\mathrm{g}=1}^{16}\left(\Delta \mathrm{S}_{\mathrm{g}} \mathrm{P}_{\mathrm{g}}^{\mathrm{t}}\right)+\sum_{\mathrm{g}=1}^{16}\left(\Delta \mathrm{P}_{\mathrm{g}} \mathrm{S}_{\mathrm{g}}^{\mathrm{t}^{\prime}}\right) .
\end{aligned}
$$

In other words, the impact of the change in group composition (the first term) is the weighted sum of changes in group population shares $\left(\Delta S_{g}\right)$ over all groups, where each group is weighted by the deviation of its initial percentage insured from the initial overall percentage insured $\left(p_{g}^{t}\right)$. A rise in a population share of a group with an above-average percentage insured will increase the overall percentage insured. The change due to within group changes in the percentage insured (the second term) is the weighted sum of changes in group percentage insured ( $\Delta P_{g}$ ) over all groups, where each group is weighted by its population share in the second year 
$\left(S_{g}^{t^{\prime}}\right)$. A decline in the percentage insured of any group will reduce the overall percentage insured.

Due to sample size limitations, we do not report findings for all of the 16 groups with work limitations, even though the shift-share analysis was applied to all 16. Instead, we report results for a) all youth (those age 15 to 18), not differentiated by sex or employment status, and b) young adults (those age 19 to 29) differentiated by sex and, separately, by employment status. The findings reported for young adults do, however, take into account changes in the joint distribution of age, sex and employment within this group.

\section{Findings and Discussion}

We present findings on: the health insurance coverage of the work-limited population ages 15-29; coverage changes between 1989 and 2000; the role of compositional changes; and coverage changes by age, sex and employment status. Detailed findings from the analysis appear in Tables 1 through 3. We discuss highlights of the findings below.

Coverage of the work-limited population ages 15-29. In 2000, at the top of the business cycle, those in the young work-limited population were substantially more likely to have insurance coverage than their counterparts in the not work-limited population (75.9 percent versus 66.7 percent). They were also much more likely to have public coverage (50.2 percent versus 8.7 percent) and much less likely to only have private coverage (36.3 percent versus 59.7 percent). (Table 1).

Coverage Changes, 1989 to 2000. Insurance coverage for the work-limited population age 15 to 29 increased from 1989 to 2000, by 5.1 percentage points (Table 2). This substantial increase is all the more remarkable when compared to the decline of 1.8 percentage points for the not work-limited population. A large increase in public coverage (11.4 percent, including those 
with both public and private coverage) is partly offset by a decline in private-only coverage (-6.3 percent). The growth in the percentage of the population with "dual coverage" (i.e., both public and private coverage), is also remarkable, even though the percentage in this category is well below the percentage in the public-only and private-only groups (10.5 percent versus 39.7 and 25.7 percent in 2000, Table 1). It is possible, however, that a part of this change is an artifact of how we inferred private coverage from the CPS data. Also, some, and perhaps many, individuals with dual coverage had public coverage in some months of the year and private coverage in other months, but not both in any single month. Because of the expansion in dual coverage, the total decline in private coverage is much less than the decline in private-only coverage. The actual decline would be larger if the expansion in dual coverage is more limited that our estimates indicate..

Role of Compositional Change. Although most of the changes in insurance status for young people with work limitations are due to changes within age, sex and employment status groups, a substantial share of the changes are due to changes in the composition of the worklimited population with respect to these characteristics. Compositional change accounts for 29 percent of the increase in overall coverage, 36 percent of the increase in public-only coverage, 33 percent of the decline in private-only coverage, and 24 percent of the increase in dual coverage (Table 3a). There were substantial shifts in the composition of this population from groups with relatively low public coverage, but relatively high employer coverage (older age groups and, within older age groups, males and those who are employed) to sub-groups with relatively high public coverage, but relatively low employer coverage (younger age groups and, within the older age groups, females and those not employed). 
These shifts reflect three phenomena. First, the number of persons age 15 to 18 (i.e., youth) with work limitations grew at a faster rate than the number of persons with work limitations in the age 19 to 29 group (i.e., young adults). As a result, the percentage of those age 15 to 18 increased from 13.7 percent to 18.8 percent (5.1 percentage points). Most of this increase reflects growth in the share of youth in the overall population age 15 to 29, which increased from 24.3 percent to 28.2 percent (3.9 percentage points). The larger growth in this share for those with work limitations was likely caused by the expansion in SSI for children, especially for males (Social Security Administration, 2001, 2002).

Second, there was a slight increase in the percentage of young adults with work limitations who are females, which likely reflects the incentives created by welfare reform (Horvath-Rose, Stapleton and O'Day, forthcoming). Third, the decline in private coverage partly reflects a decline in employment of young adults with work limitations (Horvath-Rose, Stapleton, and O’Day, 2004).

Coverage Changes by Age, Sex and Employment Status. Changes in coverage within age/sex/employment status groups vary in a manner that is consistent with expectations, given the changes in welfare and disability policy and the declines in private coverage in the broader labor market. For the older age group, changes in coverage were greatest for males, who experienced a 1.4 percentage point decline in private coverage, an 11.6 percentage point increase in public coverage, and a 5.3 percentage point increase in total coverage (Table 2). Although declines in private coverage for those employed did contribute to this decline, much more of the decline is attributable to a change in employment status. Interestingly, the decline in private coverage for employed persons with work limitations (1.8 percentage points) is less than the decline for employed persons without work limitations (4.3 percentage points) (Table 2). One 
possible explanation for this difference is that the decline in employment for those with work limitations is greater for those who are least able to obtain jobs with employer coverage than for others - reflecting changes in incentives created by the increased availability of public health insurance via SSI, as well as its increased value.

The most apparent reason for the growth in public coverage for youth is the 1990 SSI expansion for children. In fact, the increase in SSI participation due to that expansion is larger than the expansion in coverage implied by our estimates. The estimated 17.3 percentage point increase in public coverage for those with work limitations ages 15 to 18 implies that the number with public coverage in 2000 was an estimated 145 thousand larger than it would have been under the coverage rate of $1989 .{ }^{6}$ Although directly comparable SSI statistics for the same age groups and years are not available, SSA statistics for those aged 13 to 17 suggest that the number of recipients age 15 to 18 increased by approximately 200 thousand from 1989 to 2000 due to the post-Zebley expansion in eligibility ${ }^{7}$ - i.e., by more than the expansion in public coverage for

\footnotetext{
${ }^{6}$ The CPS estimate of the size of the work-limited population age 15 to 18 in 2000 is 836 million; 145 thousand is 17.3 percent of this figure.

${ }^{7}$ SSA administrative data on SSI recipients by narrow age groups has only been published since 1991, and the age groups do not quite match those we have used (see footnotes to Figure 1). The size of the expansion in SSI receipt for those in the four-year age range 15 to 18 should be approximately equal to 80 percent of the growth in SSI coverage for those in the five-year age range 13 to 17 . We first estimate the change for the 1991 to 2000, then make an adjustment for SSI growth from 1989 to 1991. The estimated SSI participation rate for those age 13 to 17 increased from 8.2 per thousand in 1991 to 14.4 per thoussand in 2000, a change of 6.2 per thousand. Combining this change with the estimated size of the 2000 population in this age range, 20.1 million, implies that the number of SSI participants in this age range was 125 thousand larger in 2000 than it would have been if the participation rate had remained at the 1991 level. The growth in the number of SSI recipients age 15 to 18 attributable to the postZebley expansion over the same period was likely about 80 percent of that value, or 100 thousand. The number of child SSI recipients had already grown considerably as the result of Zebley by 1991. From 1989 to 1991, the number of child SSI recipients grew from 265 thousand to 397 thousand, a 49.9 percent increase. If that rate of growth is applied to the 140 thousand SSI recipients age 13 to 17 in 1991, then the increase for that age group alone was 139
} 
those with work limitations. Note also that the latter figure does not include those who lost SSI benefits following PRWORA but continued to be eligible for Medicaid under PRWORA's grandfathering provisions. The size of the expansion in SSI participation may suggest that the expansion in public health insurance coverage for youth with work limitations should have been even larger than our estimates indicated. There is, however, considerable evidence that a substantial, but unknown, share of child SSI recipients after the post-Zebley expansion would have received Medicaid for other reasons in the absence of the SSI expansion. ${ }^{8}$

Much, but by no means all, of the growth in public coverage for those age 19 to 29 might also be attributable to SSI growth, in part due to the post-Zebley expansion of SSI for children, but also due to other factors that contributed to a rapid expansion in adult participation, starting in 1989 - most notably state efforts to move recipients of general assistance funds onto SSI (Rupp and Stapleton, 1995). Based on the CPS estimates, if the public coverage rate in 2000 for the estimated 3.60 million people with work limitations in this age group was the same as it was in 1989 (10.4 percentage points lower), 375 thousand fewer people would have had public coverage. Based on SSA statistics, we estimate that growth in the SSI participation rate over the same period increased the number of SSI recipients aged 19 to 29 by approximately 230 thousand. ${ }^{9}$ Of course an unknown number of those with public coverage in 2000 because of SSI

thousand, and the increase for those age 15 to 18 would presumably be about 80 percent as large, or 111 thousand. Adding this figure to the 100 thousand estimate for growth from 1991 to 2000 yields 211 thousand. Hence, growth in SSI recipients age 15 to 18 from 1989 to 2000 due to the post-Zebley expansion was on the order of 200 thousand.

${ }^{8}$ For instance, Stapleton et al. (1999, Table E.6) found that in 1993 an estimated 28 percent of SSI children lived in AFDC families. Indirect evidence on this point also comes from Garret and Glied (2000), who found that, following Zebley, child SSI participation rates increased most rapidly in states where parents and the state government had the strongest incentives to move children from AFDC to SSI.

${ }^{9}$ Based on SSA statistics (see Figure 1 notes for sources), we estimate that there were 498 thousand SSI recipients in this age group in 1991 and 632 thousand in 2000, or 11.5 and 14.9 percent of the age-group populations in those 
would have had coverage for other reasons, in the absence of the SSI expansion. Hence, although the SSI expansion can account for much of the growth in public coverage for this age group, one or more other factors must also have played a substantial role.

Expansion of Medicaid coverage for people with disabilities under other coverage categories, including medically needy programs, the Medicaid Buy-in, and various state-only programs may account for much of the increased public coverage for the young adult age group. Medicare coverage likely expanded somewhat, as well, because of growth in participation for this age group. Calculations based on published data suggest that SSDI participation growth accounts for less than 30 thousand of the estimated 375 thousand with public coverage in 2000 who would not have been covered if the percentage covered in 2000 was the same as in $1989 .{ }^{10}$ Expansion of coverage for those with HIV/AIDs not covered under Medicaid could be another source of growth in public coverage for this age group. Program statistics for the Ryan White program, first authorized by Congress in 1990, suggest that the program served several hundred thousand clients age 20 to 44 in 2000, but program statistics do not include unduplicated counts

years (4.33 million and 4.25 million, respectively). If the participation rate in 2000 had been as low as the participation rate in 1991, the number of SSI recipients in 2000 would have been lower by approximately 143 thousand. From 1989 to 1991, SSI receipt for those age 18 to 64 increased by 14.8 percent. If this rate of increase is applied to the estimated number of recipients age 19 to 29 in 1991 (498 thousand), the increase in this age group from 1989 to 1991 was 86 thousand. This figure combined with the estimated increase of 143 thousand from 1991 to 2000 yields 229 thousand.

${ }^{10}$ Based on SSA (2005, Table 5.D4) reports that, there were 125 thousand SSDI beneficiaries under the age of 30 in 1989 and 139 thousand in 2000. If we assume that all of these individuals were in the age 19 to 29 work limited population, the SSDI participation rates for this age group was 3.0 percent in 1989 and 3.9 percent in 2000. If the 2000 prevalence rate had been the same as the 1989 prevalence rate, the number on SSDI in 2000 would have been 33 thousand lower. It is likely that many of these individuals would have been on SSI, TANF or some other program that would have entitled them to public insurance (Medicaid) in the absence of the growth in SSDI. 
of clients served by age and do not include information on client health insurance coverage. ${ }^{11}$ Medicaid buy-in programs, initiated by the Balanced Budget Act of 1996 and later expanded by the Ticket to Work and Work Incentives Improvement Act in 1999, enable working individuals with disabilities with limited incomes to purchase Medicaid on a sliding scale, but the program serves about 75,000 individuals, most of whom were transferred from other Medicaid programs (Goodman and Livermore, 2004).

For young adults, increases in total public coverage for males are somewhat larger than for females, essentially eliminating the gap between public coverage for males and public coverage for females in this age group. It seems likely that this is also a consequence of the postZebley expansion of SSI, because 64 percent of child SSI recipients are male (Social Security Administration, 2000), but might also reflect the fact that about two thirds of those covered under the Ryan White program are male (HRSA, 2000).

The increase in the percentage with dual coverage is somewhat larger for youth than for young adults (6.0 versus 4.6 percentage points). This suggests that the 1990 expansion of SSI for children increased public coverage for youth who had any private coverage. Thus, youth with private dependent coverage may have become eligible for Medicaid as they became eligible for SSI. By doing so, the family would avoid paying potential deductibles and co-payments that would apply under private coverage and might maintain coverage for services or providers not covered under the private plan. The effect of the SSI expansion might also extend to those over 18: as SSI children become adults, they may be more likely to be SSI recipients than they would

\footnotetext{
11 The Health Resources and Services Administration (2000) reports that Ryan White Title I programs served 258 thousand clients age 20 to 44 in 2000, and Title II programs served 382 thousand clients in the same age range. These counts are based on provider reports, so they double count individuals who use multiple providers. Further, many clients may use both Title I and II services. The Title III and IV programs serve much smaller numbers of individuals.
} 
have been in the absence of the expansion, but they may continue to have coverage under a parent's private policy, especially if they are a student. Some individuals may also have taken advantage of more generous earnings allowances for Medicaid eligibility in some states following the Balanced Budget Act of 1997. It is also possible that some children covered by SCHIP had access to private coverage through an employed parent, although the intent of SCHIP was to provide coverage only to children without access to private coverage.

It might also be, however, that the expansion in dual coverage is an artifact of how private coverage is measured in the CPS, at least in part. Recall that those living with a spouse having employer coverage or those under age 25 and living with a parent or step parent having employer coverage are assumed to have private coverage. Increased availability of public coverage along with premium, deductible and co-payment increases for dependent coverage under private plans, as well as reduced offering of dependent coverage by some employers, could mean that the statistics overstate the increase in dual coverage, understate the overall decline in private coverage, and understate the increase in public-only coverage (but not the increase in total public coverage). If this were the case, we would expect the growth in dual coverage to be fueled primarily by those under age 25 .

Statistics on dual coverage by detailed age group appear in Table 4 . Although the growth in dual coverage is greatest for those ages 15 to 18 (6.0 percentage points), the estimated increase for the oldest age group is very substantial (3.9 percentage points), and higher than for those ages 19 to 21 . Thus, it appears that the growth in dual coverage could partially be an artifact of the method used to identify private coverage, but probably does not explain all of it. Similarly, the measurement methodology may mean that the decline in total private coverage was larger than our estimates indicate. 
It is also possible that growth in dual coverage reflects increasing numbers of people who have private coverage in some months and public coverage in other months, rather than an increase in the number having both in the same months.

Two demographic groups account for most of the overall increase in coverage for those with work limitations: youth and young men. Their experience highlights the major forces behind the observed change. The shift-share analysis shows that each of these groups accounts for 44 percent of the 5.6 percentage point increase in total coverage - a combined 88 percent of the increase. For youth, only a small share of this increase (six percentage points) is due to compositional change. As discussed above, it appears that the driving force behind the increase in coverage for youth with work limitations was the expansions in child SSI eligibility.

For young adult males, a more substantial share of the increase in coverage is accounted for by compositional change. Results from more detailed analysis of age groups (not reported) show that over 60 percent of the compositional change was due to a decline in the share of young adult males in the age 25 - 29/employed group. The decline in employment for males in this age group has been accompanied by a coverage increase; that is, the increase in their public coverage was greater than the decline in their private coverage. Much of the remaining increase in coverage for young adult males is due to substantial increases in coverage for those aged 19 to 21 and, to a lesser extent those aged 22 to 24, reflecting expansions in SSI enrollments.

\section{Conclusions}

Youth and young adults with work limitations were more likely to have health insurance coverage in 2000 than their non-work-limited cohorts. They were also more likely to have insurance coverage than they were in 1989, in sharp contrast to the decrease in insurance coverage for youth and young adults without work limitations. 
It appears that policy changes that offer expansions in SSI eligibility for children substantially increased public insurance coverage for youth with work limitations. Although the introduction of SCHIP might have played some role, the size of the expansion in SSI participation alone is sufficient to account for the increase in public coverage of youth with work limitations.

It also appears that the expansion in SSI eligibility increased coverage for young adults, many of whom were initially covered as SSI children. Expansion in the number of young adults on SSI for other reasons may also have contributed to the expansion in public coverage for young adults with work limitations, along with a more modest expansion in SSDI. Expansions in coverage under Medicaid's medically needy and Medicaid Buy-in options and other programs (e.g., Ryan White) that would include coverage for individuals in this group and the decline in employment of young adults with work limitations also contributed to the expansion.

It is possible that the SSI reforms enacted under PRWORA will reduce Medicaid coverage for youth and young adults with work limitations after 2000. SSI participation rates by age through 2004 (Figure 1) suggest, however, that the reforms only temporarily reduced the SSI participation rates in the relevant age groups; by 2004, participation rates for each group had essentially returned to their record levels from the mid 1990s. It might also be, however, that recent growth is attributed to the slow down in the economy.

The increase in the share of work-limited females with public insurance for the older age groups may partly be an artifact of how disability is measured in the CPS. There is evidence that welfare reform increased the reporting of work limitations by young mothers, to avoid the time limits and work requirements of TANF (Horvath-Rose, Stapleton and O'Day, forthcoming). Some mothers might also have been encouraged to apply for SSI by welfare agencies under 
pressure to reduce their welfare rolls (Stapleton \& Burkhauser, 2003). In the past, most such mothers would have had Medicaid coverage, via AFDC. Hence, part of the increase in coverage for young women with work limitations simply reflects the inclusion of more low-income mothers in this group. As low-income parents under AFDC and TANF are predominantly unmarried mothers, this likely contributed little to the growth in coverage for young men with work limitations.

The share of work-limited young adults with any private health insurance coverage declined substantially, based upon our proxy measure for private health insurance. This decline is due in part to the decline in private coverage for all workers and in part to the decline in employment among work-limited individuals. The actual decline in any private coverage may be greater than estimated because of the method used to impute private coverage for spouses and dependent children of workers with employer or union coverage combined with growing costs and increased access to public coverage for this same group. Over time, there may have been a decline in the percentage of such individuals who actually have employer coverage, but the imputation procedure assumes that 100 percent of such individuals have private coverage in all years. We would expect the imputation to be most problematic for those with both public and private coverage, especially for youth. In fact, we found rapid growth in dual coverage in all age groups, and the growth in dual coverage was substantially greater for youth than for young adults.

There are, however, other possible explanations of growth in dual coverage. Most importantly, the SSI expansion of eligibility for children likely meant that more children of workers with employer coverage became eligible for Medicaid. The effect on Medicaid 
enrollment was likely larger than the effect on Medicaid expenditures, because Medicaid is the payer of last resort if the individual has coverage from other sources.

Our finding that the decline in employment of young adults with work limitations contributed to the decline in private coverage may be somewhat controversial. Some have questioned the validity of employment rate declines for the population with work limitations documented by the CPS because the measured prevalence of work limitations is sensitive to the work limitation questions to the economic and policy environment (Hale, 2001; Kirchner, 1996; Kruse and Schur, 2000; Silverstein, 2005). We have addressed the effect of the business cycle on employment by comparing business cycle peaks, but the criticism in the literature is not limited to the documented effect of business cycles on prevalence. Others have shown, however, that the employment rate decline observed in the CPS parallels declines found in the National Health Interview Survey and the Survey of Income and Program Participation using broader definitions of disability that are less susceptible to the effects of changes in the economic and policy environment (Burkhauser et al., 2002; Burkhauser, Houtenville and Wittenburg, 2003; Kaye, 2003). Hence, we have to conclude that the substantial decline in private coverage and increase in public coverage that our analysis attributes to the observed decline in the employment of young adult males with work limitations is not simply an artifact of the CPS definition of disability.

One final issue may have contributed to the rise in public coverage and the decline in private coverage among young people with work limitations, concomitant with the decline in employment. The cost of health care substantially increased during the 1990s, which may have made employers more reluctant to hire people with disabilities. Buchmueller (1995) points out that higher health care premiums pose a significant disincentive for employers to hire individuals 
with chronic health conditions. Additionally, as health care costs rise through increased premiums, co-pays or coverage exclusions, significant numbers of people with disabilities may opt for public benefits over employment to obtain or retain eligibility for public Medicaid benefits. This factor may be especially important for those who need services that are provided more generously through the public than the private insurance system, such as personal assistance or adaptive technology (Hill et al., 2003). Our findings are consistent with this hypothesis, but cannot differentiate between this possible cause of the shift in coverage and others. The evidence from the literature on the employment rate decline for all working-age people with disabilities suggests that the main causes are expansions in eligibility for SSDI and SSI initiated in the mid-1980s and growth in the value of SSDI benefits relative to earnings for low-skill workers (Stapleton and Burkhauser, 2003; Burkhauser and Houtenville, 2005). The public coverage linked to these programs may contribute to their expansion and therefore to the expansion of Medicaid and Medicare.

Whatever the cause, it is apparent that there was a major shift in the responsibility for financing the health care of youth and young adults with disabilities from private insurers to public insurers during this period. The net effect for this population may have been an increase in access to coverage for care that has limited or no coverage under private policies. It likely also means that more youth and young adults with disabilities must rely on providers that accept Medicaid coverage, which can mean access to fewer providers (Long, Coughlin, and Kendall, 2002). Because most states have converted their Medicaid programs to managed care, individuals with disabilities that require the doctor's office to be physically accessible or who want specialty care may have fewer provider choices and thus be less satisfied with care (Nary et al., 2001). The shift has also increased the importance of continuity of care from youth to young 
adulthood within the public system. Finally, although we do not have expenditure estimates, it seems likely that the shift from private to public coverage for youth and young adults with work limitations made a substantial contribution to the rapidly growing cost of Medicaid. As policies to slow the growth of Medicaid expenditures are considered, it will be important to assess their potential consequences for youth and young adults with disabilities. 


\section{References}

Buchmueller, T.C. 1995. Health Risk and Access to Employer Health Insurance. Inquiry 32 (Spring) 75-86.

Burkhauser, R. V., M. Daly, A. Houtenville, and N. Nargis. 2002. Self-Reported WorkLimitation Data: What They Can and Cannot Tell Us. Demography 39(3): 541-555.

Burkhauser, R., A. Houtenville and D. Wittenburg. 2003. A User Guide to Current Statistics on the Employment of People with Disabilities. In The Decline in Employment of People with Disabilities: A Policy Puzzle, edited by D. Stapleton and R. Burkhauser. Kalamazoo, MI: W.E. Upjohn Institute.

Burkhauser, R., and A. Houtenville. 2004. Did the Employment Rate of Those with Disabilities Fall During the 1990s and Was the ADA Responsible? A Replication and Robustness Check of Acmoglu and Angrist. Cornell University Rehabilitation Research and Training Center for Economic Research on Employment Policy for People with Disabilities. December.

President's Council of Economic Advisors. 2005. Economic Report of the President, 2005. U.S. Government Printing Office.

Cutler, D. 2002. Employee Costs and the Decline in Health Insurance Coverage. NBER Working Paper 9036. National Bureau of Economic Research, Inc. July.

Ellwood, M. and L. Ku. 1998. Welfare and Immigration Reforms: Unintended Side Effects for Medicaid. Health Affairs 17 (3): 137-51.

Garrett, B. and S. Glied. 2000. Does State AFDC Generosity Affect Child SSI Participation? Journal of Policy Analysis and Management 19(2): 275-295 
Garrett, B. and J. Holahan. 2000. Welfare Leavers, Medicaid Coverage, and Private Health Insurance. Washington, D.C.: The Urban Institute. New Federalism: National Survey of America’s Families, No. B-13.

Goodman, N., \& Livermore, G. A. (2004). The Effectiveness of Medicaid Buy-In programs in Promoting the Employment of People with Disabilities. Social SecurityAdministration: Ticket to Work and Work Incentives Advisory Panel.

Hale, Thomas. 2001. The Lack of a Disability Measure in Today's Current Population Survey. Monthly Labor Review 124(6): 38-40.

Hardy, M. and E. Pavalko. 1986. The Internal Structure of Self-Reported Health Measures among Older Male Workers and Retirees. Journal of Health and Social Behavior 27(4): 346-357.

Hill, S. Livermore, G. and A. Houtenville. 2003. Rising Costs of Health Care Expenditures and the Employment of People with High Cost Chronic Conditions. The Decline in Employment of People with Disabilities: A Policy Puzzle, edited by D. Stapleton and R. Burkhauser. Kalamazoo, MI: W.E. Upjohn Institute.

Horvath-Rose, A., Stapleton, D. and B. O’Day. (2004).Trends in outcomes for young people with work disabilities: Are we making progress? Journal of Vocational Rehabilitation 21(3);175-187.

Horvath-Rose, A., Stapleton, D.C. and B. O’Day. (forthcoming). The Effects of Welfare Reform on Young Women with Disabilities. Journal of Disability Policy Studies.

Houtenville, Andrew., and Mary Daly (2003). Employment Declines Among People with Disabilities. The Decline in Employment of People with Disabilities: A Policy Puzzle, edited by D. Stapleton and R. Burkhauser. Kalamazoo, MI: W.E. Upjohn Institute. 
Kaye, Steven 2002. Employment and the Changing Disability Environment. Mimeo, Disability Statistics Center, University of California, San Francisco.

Kaye, Steven H. 2003. Were Employment Rates Affected by Changes in the Prevalence and Severity of Disability? The Decline in Employment of People with Disabilities: A Policy Puzzle, edited by D. Stapleton and R. Burkhauser. Kalamazoo, MI: W.E. Upjohn Institute.

Kirchner, Corinne 1996. Looking Under the Street Lamp: Inappropriate Uses of Measures Just Because They are There. Journal of Disability Policy Studies 7(1): 77-90.

Kruse, Douglas and Lisa Schur. 2000. Employment of People with Disabilities Following the ADA. Industrial Relations 42(1): 31-66.

Health Resources and Services Administration. 2000. Ryan White CARE Act Annual Administrative Report, 2000. Washington, DC.

Hoover, Edgar M. and Frank Giarratani, An Introduction to Regional Economics, 3rd ed., N.Y.: Knopf 1985.

Long, S.K, T.A. Coughlin, and S.J. Kendall. 2002. Unmet Need Among Rural Medicaid Beneficiaries in Minnesota. Journal of Rural Health 18 (3): 437-446.

McNeil, James. 2000. Employment, Earnings and Disability. Presented at the $75^{\text {th }}$ Annual Conference of the Western Economic Association. Retrieved March 2003 from http://www.census.gov/hhes/www/disable/emperndis.pdf

Mills, R.J. 2001. Health Insurance Coverage: 2000. Current Population Reports. P-60-215. U.S. Census Bureau.

Neri, M., Beatty, P., Dhont, K. (2001) Individuals With Disabilities Face More Constrained Health Care Choices: Especially in Managed Care. Health and Disability Data Brief. Washington, DC: NRH Center for Health and Disability Research. 
Rupp, K. and D.C. Stapleton. 1995, Determinants of the Growth in the Social Security Administration’s Disability Programs. Social Security Bulletin. 58(4): 43-70.

Social Security Administration. 1991 - 2005. Social Security Bulletin: Annual Statistical Supplement. Washington, DC.

Social Security Administration. 1999 - 2004. SSI Annual Statistical Report. Washington, DC Social Security Administration. 2004. The Ticket to Work and Work Incentives Advisory Panel Annual Report to the President and Congress Year Four.

Social Security Administration, Office of Research, Evaluation and Statistics. 2000/2001. Children Receiving SSI, December.

Silverstein, R., G. Julnes, and R. Nolan. 2005. What Policymakers Need and Must Demand From Research Regarding the Employment Rate of Persons with Disabilities. Behavioral Sciences and the Law. 23:399-448.

Stapleton, D.C., and R.V. Burkhauser. 2003. Contrasting the Employment of Single Mothers and People with Disabilities. Employment Research, Newsletter of the W.E. Upjohn Institute for Employment Research, 10(30): 3-6.

Stapleton D.C., Livermore, G.A., Scrivner, S., and A. Tucker. 1998. Exploratory Study of Health Care Coverage and Employment of People with Disabilities; Final Report. Office of the Assistant Secretary for Planning and Evaluation, U. S. Department of Health and Human Services, Washington DC: The Lewin Group.

Stapleton, D.C., M.E. Fishman, G.A. Livermore, D.C. Wittenburg, A. Tucker and S. Scrivner 1999. Policy Evaluation of the Overall Effects of Welfare Reform on SSA Programs; Final Report. Social Security Administration, Washington, DC: The Lewin Group. 
Stapleton, D. C., D.C. Wittenburg, M.E. Fishman, and G.A. Livermore. 2001/2002. Transitions from AFDC to SSI Prior to Welfare Reform. Social Security Bulletin, 16(1).List of Exhibits

Table 1: Health Insurance Status for Youth and Young Adults, 2000

Table 2: Change in Percentage Insured, 1989 to 2000

Table 3: Summary of Shift-Share Analysis of the Change in Percentage Insured for Youth and Young Adults with Work Limitations, 1989 to 2000

Table 4: Change in Percentage with Dual (Public and Private) Coverage for Younth and Young Adults with Work Limitations, by Detailed Age Categories, 1989 to 2000

Figure 1: SSI Participation Rates for Youth and Young Adults, by Age, 1991 to 2004

Figure 2: Prevalence of Work Limitations Among Youth and Young Adults, 1989-2000 
Table 1: Health Insurance Status for Youth and Young Adults, 2000

\begin{tabular}{|c|c|c|c|c|c|c|c|}
\hline \multirow[b]{2}{*}{ Population } & \multirow{2}{*}{$\begin{array}{l}\text { Pop. } \\
\text { Share }\end{array}$} & \multicolumn{6}{|c|}{ Percentage Insured } \\
\hline & & Total & $\begin{array}{l}\text { Public } \\
\text { Only }\end{array}$ & $\begin{array}{c}\text { Private } \\
\text { Only }\end{array}$ & Both & $\begin{array}{c}\text { Any } \\
\text { Public }\end{array}$ & $\begin{array}{c}\text { Any } \\
\text { Private }\end{array}$ \\
\hline Work-Limited & $100.0 \%$ & $75.9 \%$ & $39.7 \%$ & $25.7 \%$ & $10.5 \%$ & $50.2 \%$ & $36.3 \%$ \\
\hline Age $15-18$ & $18.8 \%$ & $83.8 \%$ & $37.5 \%$ & $33.7 \%$ & $12.6 \%$ & $50.1 \%$ & $46.3 \%$ \\
\hline Age $19-29$ & $81.2 \%$ & $74.1 \%$ & $40.2 \%$ & $23.9 \%$ & $10.1 \%$ & $50.2 \%$ & $33.9 \%$ \\
\hline Males & $40.8 \%$ & $71.4 \%$ & $38.3 \%$ & $22.4 \%$ & $10.6 \%$ & $48.9 \%$ & $33.0 \%$ \\
\hline Females & $40.3 \%$ & $76.8 \%$ & $42.0 \%$ & $25.3 \%$ & $9.5 \%$ & $51.5 \%$ & $34.8 \%$ \\
\hline Employed & $38.6 \%$ & $68.8 \%$ & $21.5 \%$ & $39.8 \%$ & $7.5 \%$ & $28.9 \%$ & $47.3 \%$ \\
\hline Not employed & $42.6 \%$ & $78.9 \%$ & $57.1 \%$ & $9.4 \%$ & $12.4 \%$ & $69.5 \%$ & $21.8 \%$ \\
\hline Not Work-Limited & $100.0 \%$ & $66.7 \%$ & $6.9 \%$ & $57.9 \%$ & $1.8 \%$ & $8.7 \%$ & $59.7 \%$ \\
\hline Age $15-18$ & $28.5 \%$ & $73.2 \%$ & $10.4 \%$ & $60.0 \%$ & $2.8 \%$ & $13.2 \%$ & $62.9 \%$ \\
\hline Age $19-29$ & $71.5 \%$ & $64.0 \%$ & $5.5 \%$ & $57.1 \%$ & $1.4 \%$ & $6.9 \%$ & $58.5 \%$ \\
\hline Males & $35.4 \%$ & $61.0 \%$ & $2.7 \%$ & $57.6 \%$ & $0.8 \%$ & $3.4 \%$ & $58.3 \%$ \\
\hline Females & $36.1 \%$ & $67.0 \%$ & $8.4 \%$ & $56.7 \%$ & $2.0 \%$ & $10.4 \%$ & $58.7 \%$ \\
\hline Employed & $60.4 \%$ & $66.5 \%$ & $4.2 \%$ & $61.0 \%$ & $1.3 \%$ & $5.5 \%$ & $62.3 \%$ \\
\hline Not employed & $11.1 \%$ & $50.9 \%$ & $13.0 \%$ & $36.1 \%$ & $1.8 \%$ & $14.8 \%$ & $37.9 \%$ \\
\hline
\end{tabular}

Source: Authors' analysis of the March Supplements for the 1999 - 2001 Current Population Surveys. Estimates are based on data pooled over the three-year period.

Notes: "Pop. Share" refers to the share of the relevant population in the group indicated. "Public" coverage includes Medicaid, Medicare and a variety of much smaller public programs. "Private” coverage includes employer/union coverage as an employee or employee dependent as well as private coverage purchased on the independent market. "Public Only" means public coverage, but no private coverage; "Private Only” means private coverage, but no public coverage;“Both” refers to both public and private coverage, “Any Public” is the sum of Public Only and Both, and "Any Private” is the sum of Private Only and Both. 
Table 2: Change in Percentage Insured, 1989 to 2000

\begin{tabular}{|c|c|c|c|c|c|c|c|}
\hline & \multirow{2}{*}{$\begin{array}{c}\text { Change } \\
\text { Population }\end{array}$} & \multicolumn{5}{|c|}{ Change in Percentage Insured, 1989 to 2000 } \\
\cline { 3 - 8 } & Share & Total & $\begin{array}{c}\text { Public } \\
\text { Only }\end{array}$ & $\begin{array}{c}\text { Private } \\
\text { Only }\end{array}$ & Both & $\begin{array}{c}\text { Total } \\
\text { Public }\end{array}$ & $\begin{array}{c}\text { Total } \\
\text { Private }\end{array}$ \\
\hline Work Limited & $\mathbf{0 . 0}$ & $\mathbf{5 . 1}$ & $\mathbf{6 . 4}$ & $-\mathbf{6 . 3}$ & $\mathbf{4 . 9}$ & $\mathbf{1 1 . 4}$ & $\mathbf{- 1 . 4}$ \\
Age 15 - 18 & 5.1 & 10.0 & 11.2 & -7.2 & 6.0 & 17.3 & -1.2 \\
Age 19-29 & -5.1 & 3.7 & 5.8 & -6.7 & 4.6 & 10.4 & -2.1 \\
Males & -6.7 & 5.3 & 6.8 & -6.3 & 4.9 & 11.6 & -1.4 \\
Females & 1.6 & 1.1 & 4.2 & -7.6 & 4.4 & 8.6 & -3.1 \\
Employed & -10.7 & 2.7 & 4.5 & -5.6 & 3.8 & 8.3 & -1.8 \\
Not employed & 5.6 & 2.7 & -0.5 & -1.4 & 4.6 & 4.1 & 3.3 \\
\hline Not Work-Limited & $\mathbf{0 . 0}$ & $\mathbf{- 1 . 8}$ & $\mathbf{0 . 5}$ & $\mathbf{- 3 . 1}$ & $\mathbf{0 . 8}$ & $\mathbf{1 . 3}$ & $\mathbf{- 2 . 3}$ \\
Age 15 - 18 & 3.8 & 2.1 & 1.2 & -0.6 & 1.6 & 2.7 & 0.9 \\
Age 19 - 29 & -3.8 & -3.6 & 0.1 & -4.1 & 0.5 & 0.6 & -3.6 \\
Males & -1.6 & -3.0 & 0.6 & -3.8 & 0.2 & 0.8 & -3.6 \\
Females & -2.2 & -4.0 & -0.4 & -4.4 & 0.7 & 0.4 & -3.6 \\
Employed & -3.8 & -2.7 & 1.6 & -4.9 & 0.6 & 2.2 & -4.3 \\
Not employed & 0.0 & -7.6 & -9.3 & 1.7 & 0.0 & -9.3 & 1.7 \\
\hline
\end{tabular}

Source: Authors' analysis of the March Supplements for the 1988 - 1990 and 1999 - 2001 Current Population

Surveys. Estimates are based on data pooled over each three-year period.

Notes: See Table 1 notes for column definitions. 
Table 3: Summary of Shift-Share Analysis of the Change in Percentage Insured for Youth and Young Adults with Work Limitations, 1989 to 2000

\begin{tabular}{|c|c|c|c|c|c|c|c|}
\hline \multirow{3}{*}{ Insurance Category } & \multirow{3}{*}{ Total } & \multirow{3}{*}{$\begin{array}{c}\text { Age } \\
15-18\end{array}$} & \multicolumn{5}{|c|}{ Age 22 - 29} \\
\hline & & & \multirow{2}{*}{ Total } & \multirow{2}{*}{ Males } & \multirow{2}{*}{ Females } & \multicolumn{2}{|c|}{ Employment Status } \\
\hline & & & & & & Yes & No \\
\hline & & & Chang & Percenta & Insured & & \\
\hline \multicolumn{8}{|l|}{ Total } \\
\hline Due to Change in Share & 1.5 & 0.3 & 1.1 & 0.8 & 0.4 & 0.4 & 0.7 \\
\hline Due to Change in \% Insured & 3.6 & 1.9 & 1.7 & 1.5 & 0.2 & 0.7 & 1.0 \\
\hline Total & 5.1 & 2.2 & 2.8 & 2.2 & 0.6 & 1.1 & 1.7 \\
\hline \multicolumn{8}{|l|}{ Public Only } \\
\hline Due to Change in Share & 2.3 & 0.2 & 2.2 & 1.4 & 0.8 & 1.4 & 0.8 \\
\hline Due to Change in \% Insured & 4.1 & 1.7 & 2.4 & 1.4 & 1.0 & 1.9 & 0.5 \\
\hline Total & 6.4 & 1.9 & 4.6 & 2.7 & 1.8 & 3.3 & 1.3 \\
\hline \multicolumn{8}{|l|}{ Private Only } \\
\hline Due to Change in Share & -2.1 & 0.1 & -2.1 & -1.3 & -0.8 & -1.4 & -0.7 \\
\hline Due to Change in $\%$ Insured & -4.2 & -0.9 & -3.3 & -1.1 & -2.2 & -2.4 & -1.0 \\
\hline Total & -6.3 & -0.8 & -5.5 & -2.5 & -3.0 & -3.8 & -1.7 \\
\hline \multicolumn{8}{|l|}{ Both } \\
\hline Due to Change in Share & 1.2 & 0.1 & 1.1 & 0.7 & 0.4 & 0.5 & 0.6 \\
\hline Due to Change in $\%$ Insured & 3.8 & 1.1 & 2.6 & 1.3 & 1.4 & 1.2 & 1.5 \\
\hline Total & 4.9 & 1.2 & 3.7 & 2.0 & 1.8 & 1.6 & 2.1 \\
\hline \multicolumn{8}{|l|}{ Total Public } \\
\hline Due to Change in Share & 3.5 & 0.2 & 3.3 & 2.1 & 1.2 & 1.8 & 1.5 \\
\hline Due to Change in \% Insured & 7.8 & 2.8 & 5.0 & 2.6 & 2.4 & 3.1 & 1.9 \\
\hline Total & 11.4 & 3.1 & 8.3 & 4.7 & 3.6 & 4.9 & 3.4 \\
\hline \multicolumn{8}{|l|}{ Total Private } \\
\hline Due to Change in Share & -0.9 & 0.2 & -1.0 & -0.6 & -0.4 & -1.0 & -0.1 \\
\hline Due to Change in \% Insured & -0.5 & 0.2 & -0.7 & 0.1 & -0.8 & -1.2 & 0.5 \\
\hline Total & -1.4 & 0.4 & -1.7 & -0.5 & -1.2 & -2.2 & 0.4 \\
\hline
\end{tabular}


Table 3 (continued): Summary of Shift-Share Analysis of the Change in Percentage Insured for Youth and Young Adults with Work Limitations, 1989 to 2000

\begin{tabular}{|c|c|c|c|c|c|c|c|}
\hline \multirow{3}{*}{ Insurance Category } & \multirow{3}{*}{ Total } & \multirow{3}{*}{$\begin{array}{c}\text { Age } \\
15-18\end{array}$} & \multicolumn{5}{|c|}{ Age $22-29$} \\
\hline & & & \multirow{2}{*}{ Total } & \multirow{2}{*}{ Males } & \multirow{2}{*}{ Females } & \multicolumn{2}{|c|}{ Employment Status } \\
\hline & & & & & & Yes & No \\
\hline & & & Perce & e of Tote & hange & & \\
\hline \multicolumn{8}{|l|}{ Total } \\
\hline Due to Change in Share & $29 \%$ & $6 \%$ & $23 \%$ & $15 \%$ & $8 \%$ & $8 \%$ & $15 \%$ \\
\hline Due to Change in \% Insured & $71 \%$ & $38 \%$ & $33 \%$ & $29 \%$ & $4 \%$ & $14 \%$ & $19 \%$ \\
\hline Total & $100 \%$ & $44 \%$ & $56 \%$ & $44 \%$ & $12 \%$ & $23 \%$ & $33 \%$ \\
\hline \multicolumn{8}{|l|}{ Public Only } \\
\hline Due to Change in Share & $46 \%$ & $3 \%$ & $43 \%$ & $28 \%$ & $16 \%$ & $27 \%$ & $16 \%$ \\
\hline Due to Change in $\%$ Insured & $80 \%$ & $34 \%$ & $47 \%$ & $27 \%$ & $20 \%$ & $38 \%$ & $9 \%$ \\
\hline Total & $127 \%$ & $37 \%$ & $90 \%$ & $54 \%$ & $36 \%$ & $65 \%$ & $25 \%$ \\
\hline \multicolumn{8}{|l|}{ Private Only } \\
\hline Due to Change in Share & $-41 \%$ & $1 \%$ & $-42 \%$ & $-26 \%$ & $-16 \%$ & $-28 \%$ & $-14 \%$ \\
\hline Due to Change in $\%$ Insured & $-84 \%$ & $-18 \%$ & $-66 \%$ & $-22 \%$ & $-43 \%$ & $-47 \%$ & $-19 \%$ \\
\hline Total & $-124 \%$ & $-16 \%$ & $-108 \%$ & $-49 \%$ & $-59 \%$ & $-75 \%$ & $-33 \%$ \\
\hline \multicolumn{8}{|l|}{ Both } \\
\hline Due to Change in Share & $24 \%$ & $2 \%$ & $22 \%$ & $14 \%$ & $8 \%$ & $9 \%$ & $13 \%$ \\
\hline Due to Change in \% Insured & $74 \%$ & $22 \%$ & $52 \%$ & $25 \%$ & $27 \%$ & $23 \%$ & $29 \%$ \\
\hline Total & $98 \%$ & $24 \%$ & $74 \%$ & $39 \%$ & $35 \%$ & $32 \%$ & $42 \%$ \\
\hline \multicolumn{8}{|l|}{ Total Public } \\
\hline Due to Change in Share & $70 \%$ & $5 \%$ & $65 \%$ & $41 \%$ & $24 \%$ & $36 \%$ & $29 \%$ \\
\hline Due to Change in \% Insured & $155 \%$ & $56 \%$ & $99 \%$ & $52 \%$ & $47 \%$ & $61 \%$ & $38 \%$ \\
\hline Total & $224 \%$ & $60 \%$ & $164 \%$ & $93 \%$ & $71 \%$ & $97 \%$ & $67 \%$ \\
\hline \multicolumn{8}{|l|}{ Total Private } \\
\hline Due to Change in Share & $-17 \%$ & $3 \%$ & $-21 \%$ & $-13 \%$ & $-8 \%$ & $-19 \%$ & $-1 \%$ \\
\hline Due to Change in $\%$ Insured & $-9 \%$ & $4 \%$ & $-14 \%$ & $3 \%$ & $-16 \%$ & $-24 \%$ & $10 \%$ \\
\hline Total & $-27 \%$ & $7 \%$ & $-34 \%$ & $-10 \%$ & $-24 \%$ & $-43 \%$ & $8 \%$ \\
\hline
\end{tabular}

Source: Authors' analysis of the March Supplements for the 1988 - 1990 and 1999 - 2001 Current Population

Surveys. Estimates are based on data pooled over each three-year period.

Notes: See Table 1 notes for definitions of insurance categories. See text for an explanation of the shift-share methodology. 
Table 4: Change in Percentage with Dual (Public and Private) Coverage for Youth and Young Adults with Work Limitations, by Detailed Age Categories, 1989 to 2000

\begin{tabular}{|c|r|r|c|}
\hline Category & \multicolumn{1}{|c|}{$\mathbf{1 9 8 9}$} & \multicolumn{1}{c|}{$\mathbf{2 0 0 0}$} & Change \\
\hline Age 15 - 18 & $6.6 \%$ & $12.6 \%$ & 6.0 \\
Age 19 - 21 & $10.8 \%$ & $13.0 \%$ & 2.2 \\
Age 22 - 24 & $11.7 \%$ & $16.3 \%$ & 4.6 \\
Age 25 - 29 & $1.2 \%$ & $5.1 \%$ & 3.9 \\
\hline
\end{tabular}

Source: Authors’ analysis of the March Supplements for the 1988 - 1990 and 1999 - 2001 Current Population Surveys. Estimates are based on data pooled over each three-year period. 


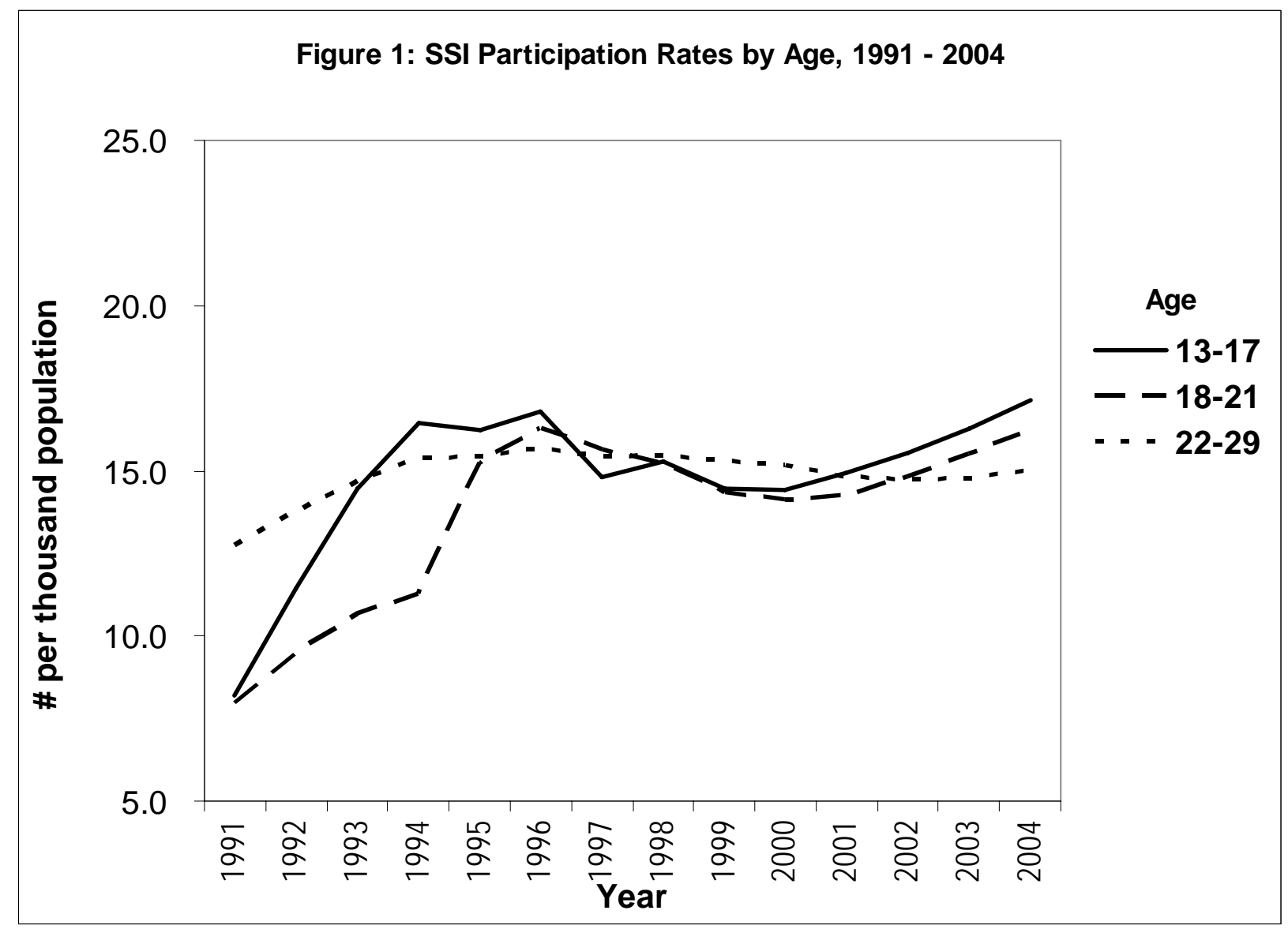

Sources:

SSI recipients

1999 to 2004: SSA, SSI Annual Statistical Report, 1999 through 2004

1991 to 1998: SSA Social Security Bulletin Annual Statisitcs Supplement, 1991 through 1998.

Age group 13-17 calculated by multiplying the reported value for age group 10-17 by 5/8.

Population

2000 to 2004: Census 2001 - 2004 Age Groups and Sex, accessed on November 30, 2005, http://www.census.gov/popest/national/asrh/2004_nat_af.html

1991 to 2000: Census 1990-2000 Age Groups and Sex, accessed on November 30, 2005, http://www.census.gov/popest/archives/EST90INTERCENSAL/US-EST90INT-datasets.html 
Figure 2: Prevalence of Work Limitations

Among Youth and Young Adults, 1982-2000

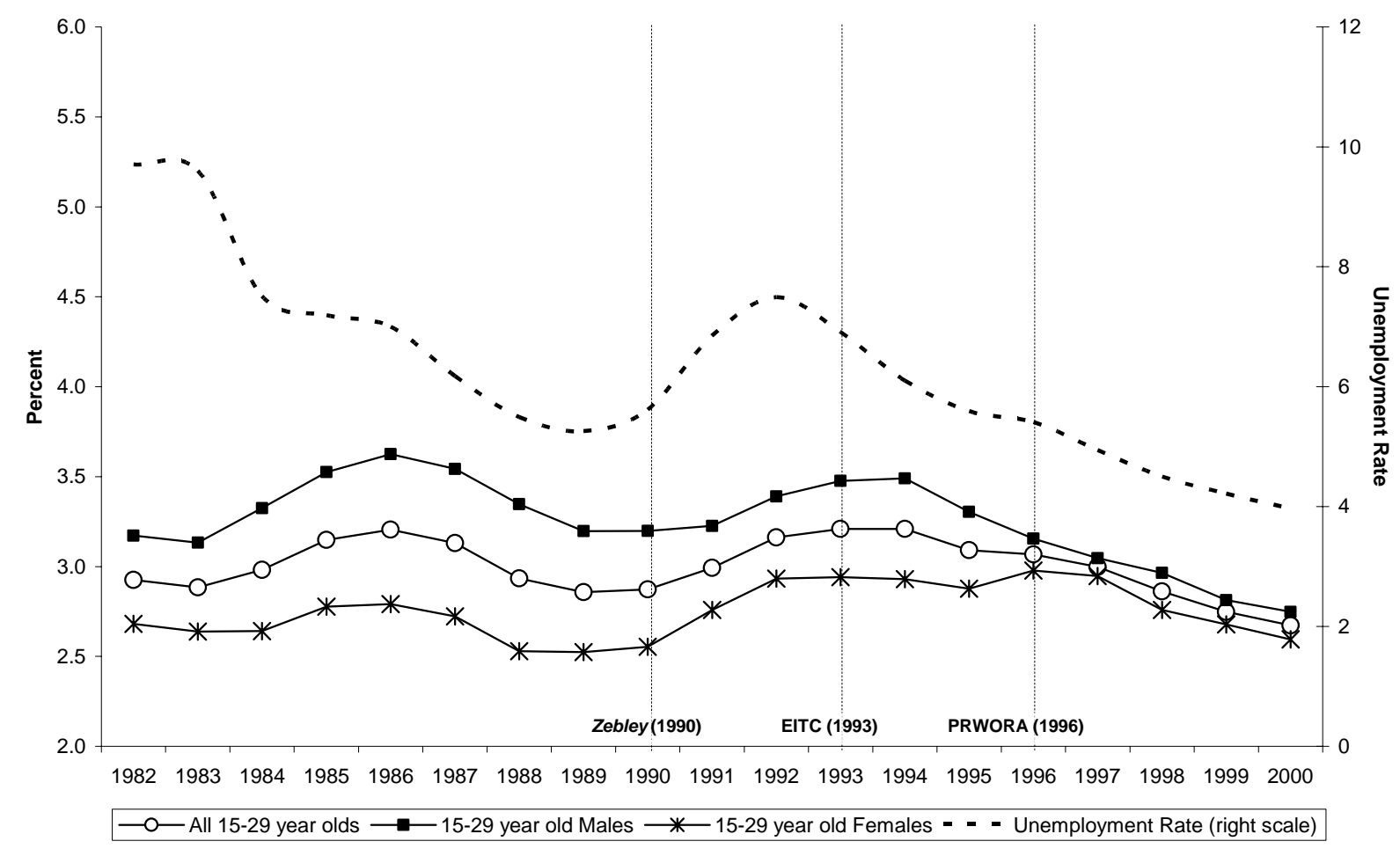

Sources:

Prevalence of work limitations: Authors’ analysis of the March Supplements for the 1981 - 2001 Current Population Surveys. Annual estimates are based on data pooled over the three-year period centered on the year indicated. Unemployment Rate: President’s Council of Economic Advisors (2005). 
For more information about the Cornell RRTC contact:

Susanne M. Bruyère, Ph.D.

Project Director

Cornell University

106 ILR Extension Building

Ithaca, NY 14853-3901

tel (607) 255-7727

fax (607) 255-2763

tty (607) 255-2891

emailssmb23@cornell.edu

web www.ilr.cornell.edu/rrtc 